\title{
CORRÊA, Amélia Siegel. Alfredo Andersen: Retratos e paisagens de um norueguês caboclo. São Paulo: Alameda Casa Editorial, 2014. 305p.
}

Isaura Maria Rigitano de Limas ${ }^{1}$

- Enviado em 30/01/2016

- Aprovado em 23/02/2016

Por que um norueguês ficou conhecido como o pai da pintura paranaense? Por que ele decidiu sair de sua terra natal e morar permanentemente no Paraná? Quais foram os motivos que o tornaram o principal retratista da elite paranaense, recém emancipada da Província de São Paulo, em 1853? Partindo dessas questões, por meio do livro Alfredo Andersen - Retratos de um norueguês caboclo, Amélia Siegel Corrêa propõe recuperar a complexa trama de relações sociais em curso no Paraná no período da Primeira República.

Produto de seu doutoramento em Sociologia pela Faculdade de Filosofia, Letras e Ciências Humanas da Universidade de São Paulo, a obra de Corrêa busca reconstruir a trajetória de Andersen e as possíveis conexões entre a sua vida e os acontecimentos históricos e sociais no Paraná do fim do século XIX e início do século XX.

No decorrer de 6 capítulos, a autora investiga o percurso do artista desde os primeiros anos de produção criativa na Noruega até o Brasil, ao se tornar o conhecido pintor do Paraná, analisando toda a sociabilidade entremeada em suas relações. O livro também contém um riquíssimo caderno de imagens e toda sua produção artística catalogada, como ferramenta para a contextualização sociocultural.

\footnotetext{
1 Isaura Maria Rigitano de Limas é bacharel e licenciada em Dança pela PUC-PR. Professora da ESL e tradutora. Endereço eletrônico: irigitano@ hotmail.com.
} 
Mesmo com o desenvolvimento econômico gerado pela ascensão da erva-mate, o estado ainda não possuía uma cultura própria paranaense. Nesse cenário, Andersen passa a ter um importante papel. Mas por que foi ele a se tornar o pintor de referência para essa sociedade que tenta estabelecer uma singularidade dentro da identidade nacional? Para responder essa questão a autora volta ao início de sua trajetória.

Nascido em 1860 em Kristiansand, pequena cidade portuária na Noruega, Alfred Emil Andersen logo cedo se interessa pela pintura por causa de um problema de saúde, uma bronquite crônica. Aos 14 anos, ele começa a frequentar a escola de desenho, mostrando em seus primeiros cadernos grande habilidade. Seu pai era capitão de navio, o que proporcionou ao jovem a realização de viagens que contribuíram para aguçar seu imaginário. Estudou depois na Academia Real de Belas Artes de Copenhagen e residiu na capital dinamarquesa por quase cinco anos. Insatisfeito com a rigorosa sistemática de ensino, ele abandona a Academia, não sem antes incorporar a cultura de seu país. Conforme a autora ressalta, toda vivência cultural na Dinamarca era reflexo do movimento cultural norueguês, que tinha o trabalhador camponês como " símbolo de uma essência nacional intocada por influências estrangeiras, esquemas culturais identitários fortes e constituintes do seu olhar, e que ele aplicará ao que vê no Brasil."2

Andersen também chegou a passar por Paris, considerada na época a Meca para os artistas estrangeiros por causa de uma política deliberada do governo francês. Mas ele não foi à cidade como artista plástico e sim como jornalista, cobrindo a Exposição Universal de 1889. Essas circunstâncias sugerem a sua dificuldade de viver da pintura e Corrêa pontua uma das razões para isso. Mesmo Copenhagen sendo uma cidade cosmopolita em relação a Kristiansand, ainda assim "a distância da formação de Andersen dos principais centros o deixou longe das redes e dos códigos plásticos necessários para um melhor posicionamento no campo artístico em sua terra natal." ${ }^{3}$

A pintura de Andersen, portanto, estava muito longe da vanguarda, o que também poderia ser um indicativo da necessidade de abdicar de sua cidade natal e vislumbrar uma vida em outro lugar. Outra importante questão se dá pelo fato de Andersen estar vinculado aos preceitos provincianos e nacionalistas de Wergeland, poeta nascido em Kristiansand, que era contra a corrente interessada em conectar a Noruega com o resto da Europa pela modernização.

\footnotetext{
${ }^{2}$ CORRÊA, Amélia Siegel. Alfredo Andersen: Retratos e paisagens de um norueguês caboclo. São Paulo. Alameda Casa Editorial,2014, p.5
}

${ }^{3}$ CORRÊA, Amélia Siegel. Alfredo Andersen: Retratos e paisagens de um norueguês caboclo. São Paulo. Alameda Casa Editorial,2014, p. 52 
Wergeland queria manter uma tradição verdadeiramente norueguesa, pois acreditava que cada povo e cada época possuíam sua forma de expressão, sua particularidade, sua herança cultural. A autora aponta que essa relação entre a pintura e as questões de cunho social na Noruega pode ser em parte transportada para a ideia de construção do regionalismo paranaense.

Ao proporcionar diversas viagens a Andersen, seu pai tinha como propósito incentivá-lo a seguir a carreira naval. Porém, isso acabou fomentando no jovem uma curiosidade e o gosto pela pintura, por conhecer novas terras. Andersen veio ao Brasil pela primeira vez no fim de 1891 e teve o seu primeiro contato com o povo brasileiro na Paraíba.

De volta à Europa, ficou alguns meses na Inglaterra e quando decidiu retornar à sua cidade natal descobriu que boa parte dela foi destruída por um incêndio. Também recebeu uma recusa para uma posição como professor de desenho em Katedraskole, por ser um livre-pensador. Diante de um cenário tão desanimador, ele nem chegou a retornar à Noruega. Em 1892, embarca em um navio em direção à Argentina, mas acabou permanecendo na parada em Paranaguá.

E por que ele ficou? Segundo Corrêa, porque já tinha um conhecimento prévio do país, porque o povo era extremamente amigável e o mais importante, porque Andersen verificou que as condições de vida em Paranaguá eram extraordinariamente baratas. Logo que se estabeleceu, passou a competir com os fotógrafos na produção de retratos. E são os retratos o objeto de análise da pesquisa de Corrêa. A autora explica que selecionou quantidade substantiva dos retratos da autoria de Andersen ao longo de sua vida no Brasil para apreender "pelo contexto social e pelas redes de relações em que foram produzidos, a relação entre arte, cultura e política no Paraná e a posição ocupada pelo pintor nessa configuração." 4

Portanto, é através da retratística de personalidades sociais e políticas do Paraná que Corrêa traça seu estudo, não tendo como meta fazer uma análise estética e sim, através das imagens, mostrar o gosto local, a ordem social do final do século XIX e a busca da modernização pela elite da época.

A pintura naturalista de Andersen, apesar de estar perdendo espaço na Europa vanguardista, foi bem recebida no Brasil por sua formação e origem estrangeira, o que era um símbolo de status. Mas ao longo de toda sua vida ele nunca teve uma situação financeira confortável e vivia de forma modesta. Chegou até a prestar vários outros tipos de serviço, como arquiteto e decorador de residências, para compor sua renda familiar.

\footnotetext{
${ }^{4}$ CORRÊA, Amélia Siegel. Alfredo Andersen: Retratos e paisagens de um norueguês caboclo. São Paulo. Alameda Casa Editorial,2014, p. 89
} 
Mesmo tendo contato com a elite, seu acesso era restrito e seus laços afetivos se limitavam a populares e outros estrangeiros que estavam no Paraná para a construção da estrada de ferro entre Curitiba e Paranaguá. Seu casamento com uma nativa de origem humilde, Ana de Oliveira, conforme a autora, pode ter contribuído para que, apesar de ter circulado nas altas rodas locais e de ser considerado um gentleman, Andersen não fazia parte delas. Mas com seu status de artista europeu e com uma formação acadêmica mais consistente do que os demais pintores da época no litoral, possuir um retrato por Andersen trazia para a elite um verniz, a oportunidade de possuir um símbolo de requinte que os colocava em um lugar de distinção social em Paranaguá.

Andersen deslocou-se a Curitiba para atender a encomendas e em 1903 acabou se mudando definitivamente para a capital, quando inicia uma rede de relacionamentos e começa a circular entre literatos e políticos. Suas encomendas passaram então a fazer parte de uma estratégia de diferenciação usada pela recente burguesia proveniente das elites ervateiras paranaenses. Os retratos de Andersen, portanto, tinham várias funções: a de prestar homenagens, de simbolizar poder e prestígio, de perpetuar a imagem de poder político, de diferenciar as classes e também reforçar a cultura de uma identidade para o Paraná.

O relacionamento de maior influência nesse contexto é com Romário Martins, figura chave na criação do paranismo. Na correspondência trocada entre o inventor do paranismo e o pai da pintura paranaense percebe-se como Martins impulsiona a carreira do artista e articula encomendas oficiais para o amigo, incluindo-o sempre que possível. Martins desempenha papel importante na trajetória de Andersen no Paraná, inclusive sugeriu o tema de pinheirais para as suas obras, reforçando a construção do imaginário da identidade paranista.

Corrêa ressalta que Andersen é considerado o pai da pintura paranaense porque foi o primeiro intérprete da paisagem local, paisagem essa que tem um importante lugar simbólico na constituição do regionalismo paranaense. Outras importantes personalidades políticas, como Vicente Machado e Affonso Alves de Camargo, também contribuíram para a permanência do artista no Paraná, que teria aqui ficado para contribuir com o desenvolvimento do povo paranaense.

Visando esse desenvolvimento, Andersen retoma uma função que remetia à sua juventude na Noruega, a de lecionar, mas também como uma outra forma de garantir a sua sobrevivência. Começou lecionando em seu ateliê e depois na Escola de Belas Artes e Indústrias, no Colégio Paranaense e na Escola Alemã, o que proporcionou uma abertura para as artes plásticas do Estado.

Através da análise iconográfica da produção retratística de Andersen, o livro de Amélia Siegel Corrêa faz o resgate da rede de relacionamentos sociais e políticos no Paraná em um recorte temporal situado na Primeira República. Também, como expõe a autora, essa análise se mostrou 
"um terreno fecundo para vislumbrar as redes de trocas e favores que envolviam políticos, literatos

e artistas plásticos no Paraná, mas também dos seus anseios por melhores posições no campo nacional". 5

${ }^{5}$ CORRÊA, Amélia Siegel. Alfredo Andersen: Retratos e paisagens de um norueguês caboclo. São Paulo. Alameda Casa Editorial,2014, p. 262 